Research Article

\title{
Effect of Metformin on Bcl-2/Bax Expression Ratio and Endometrial Implants: A Mouse Model in Endometriosis Study
}

\author{
Inu Mulyantoro ${ }^{1 *}$, Oktoria Indrapraja ${ }^{1}$, Widjiati ${ }^{2}$, and Noor Pramono Noerpramana ${ }^{1}$ \\ ${ }^{1}$ Reproductive Endocrinology and Fertility Division, Department of Obstetrics and Gynaecology, Faculty of \\ Medicine, Diponegoro University, Semarang, Indonesia \\ ${ }^{2}$ Department of Veterinary Embryology, Faculty of Veterinary Medicine, Airlangga University, Surabaya, Indonesia
}

\section{Article Info}

History

Received: 12 Jun 2020

Accepted: 18 Aug 2020

Available: 31 Aug 2020

\begin{abstract}
Background: Endometriosis is a gynaecological disorder characterised by the presence of endometrial tissue outside the uterine cavity. Apoptosis, regulated by the balance of $\mathrm{Bcl}-2 / \mathrm{Bax}$, plays an important role in the endometrial improvement. Metformin, an insulin sensitizer that is known to have beneficial effect in the endometriosis treatment, is expected to lower $\mathrm{Bcl}-2 / \mathrm{Bax}$ expression ratio and reduce endometrial implants.

Objective: To explore the effect of metformin on the Bcl-2/Bax expression ratio and endometrial implant area of endometriosis-induced mice.

Methods: This experimental study used 3-month old $33 \mathrm{BALB} / \mathrm{c}$ mice of endometriosis that were randomly and equally divided into three groups (P0, P1, and $\mathrm{P} 2)$. On the 15th day, the $\mathrm{P} 0$ group was first terminated for Bcl-2/Bax examination and the size of endometrial implants. The P1 group was given aquabidest, whereas the P2 group was given metformin $4 \mathrm{mg} /$ day for 14 days. The immunohistochemistry of Bcl2/Bax expression were performed from cavum abdomen and pelvis peritoneal tissues of the mice and measured by the Remmele Scale Index, whereas the extracted mice' endometrial implants were analysed with computer tracing method. All data normality test was calculated with Shapiro-Wilk test. The mean difference test of all groups was analysed using the one-way ANOVA test, whereas the mean difference test between groups was completed using the Unpaired T-test (LSD/Least Significance Difference). Results: The Bcl-2/Bax expression ratio and endometrial implant area in the $\mathrm{P} 2$ group were significantly lower compared to P0 and P1 ( $\mathrm{p}<0.001)$. There were no significant differences in the $\mathrm{Bcl}-2 / \mathrm{Bax}$ expression ratio or endometrial implant area in $\mathrm{P} 0$ and $\mathrm{P} 1$ ( $\mathrm{p}>0.05)$.

Conclusion: Metformin may be a potential effective drug treatment for endometriosis by decreasing $\mathrm{Bcl}-2 / \mathrm{Bax}$ expression ratio and endometrial implants.
\end{abstract}

Keywords: Metformin; endometriosis; Bcl-2/Bax ratio; endometriosis implants Permalink/ DOI: https://doi.org/10.14710/jbtr.v6i2.8113

\section{INTRODUCTION}

Endometriosis is a gynaecological condition identified with endometrial-like tissue lesions on the outer side of the uterine cavity, such as stroma and endometrial-like glands, and linked with pain on pelvic area and infertility. ${ }^{1}$

\footnotetext{
* Corresponding author:

E-mail: dr. Inu Mulyantoro, $\operatorname{SpOG}(\mathrm{K})$

(Inu Mulyantoro)
}

This oestrogen-dependent disorder emits proliferative properties, signified with the increase of progesterone resistance. $^{2}$ However, it is known that the pathogenesis of endometriosis involves apoptosis and angiogenesis. Apoptosis has a major role in the development of endometriosis, in which decreased rate of apoptosis will exacerbate the condition of endometriosis. ${ }^{3}$ Endometriosis occurs frequently in women of reproductive age, although the etiopathology of this disorder is not clearly understood. The estimated 
prevalence of endometriosis in reproductive-age women is around $10 \% .^{1}$

The apoptosis process is regulated by various agents, including one of the most important regulators in the apoptosis mechanism, B-cell lymphoma 2 (Bcl-2) family, which is first discovered as the proto-oncogene in B-cell lymphoma. The excessive expression of Bcl-2 protects lymphocytes from apoptosis and enables endometriosis cells to survive in a longer period. Bcl-2 is expressed in hormone-sensitive tissues, such as endometrium, prostate, and breasts. In the other hand, Bcl-2 associated X (Bax) has pro-apoptotic ability that will further encourage death susceptibility. ${ }^{3}$ The balance between Bcl-2 and Bax is believed to have a major role in determining the possibility of apoptosis. The higher apoptotic activity rate is always associated with the lower $\mathrm{Bcl}-2 / \mathrm{Bax}$ levels ratio. It is assumed that the proportion of $\mathrm{Bcl}-2 / \mathrm{Bax}$ is a significant key factor in causing the cells to be resistant to apoptosis stimulation. ${ }^{5,6}$

Table 1. Bcl-2 expression of Balb/c mice in all groups

\begin{tabular}{cccc}
\hline Group & Mean \pm SD & Median & (Min-Max) \\
\hline P0 & $8.973 \pm 2.1809$ & 9.200 & $(5.5-12.0)$ \\
P1 & $3.764 \pm 2.4188$ & 2.600 & $(2.0-8.5)$ \\
P2 & $2.773 \pm 0.5081$ & 3.000 & $(2.0-3.8)$ \\
\hline
\end{tabular}

In general, the options for the management of endometriosis include surgery and medical therapy, which are intended to lower oestrogen production, cause atrophy of the implant endometrial tissues, and stop the menstrual cycle. The effectiveness of endometriosis therapy is usually measured by its effectiveness in suppressing endometriosis growth, overcoming pain, and improving infertility conditions. An ideal therapy for endometriosis aims to revert the established endometriosis lesions without causing side effects that are associated with oestrogen deficiency status. Various drugs have been used to treat endometriosis, including GnRH agonist, GnRH antagonist, progestagen, aromatase inhibitor, danazol, gestrinon, selective oestrogen receptor modulator (SERM), progesterone inhibitors, selective progesterone receptor modulator, angiogenesis inhibitors, as well as immunomodulators. ${ }^{7}$ Unfortunately, as of now, there is no single drug that can completely cure endometriosis. In certain circumstances, the unfavourable consequences of consuming the aforementioned drugs may force the long-term treatment of endometriosis to be stopped. Several studies suggest that medical therapy may prevent conception and not be beneficial for fertility. ${ }^{8-10}$ In addition, the recurrence rate of the management of endometriosis still reaches 60 percent. ${ }^{11-13}$ There is considerable proof to show that the efficacy of oestrogen affects and encourages endometriosis. Oestrogen is thought to function through the MAPK and PI3K/AKT/mTOR pathways, thus, increasing the likelihood of targeting the PI3K pathway is likely to be a new approach for the treatment of endometriosis. $^{14,15}$

Metformin (1,1-dimethylbiguanide hydrochepatic lipaseoride) is an oral anti-diabetic drug that has been reported to show a positive impact in menstruation cycle, hormonal profile, insulin concentration, insulin sensitivity, insulin resistance, and androgen concentration in patients. ${ }^{16-18}$ This drug has been considered the potential treatment for endometriosis and the effectiveness of metformin has been tested in several studies through several pathways. Metformin successfully decreases inflammation in endometriosis patients by reducing pro-inflammatory cytokines and growth factors, such as IL-6, IL-8, and VEGF. ${ }^{19}$ Metformin is also equipped with anti-tumour effects by activating AMP-activated kinase (AMPK) and inhibiting rapamycin (MTOR) in mammalian targets, which are the transcription-signal-pathway for proliferative activity. Thus, metformin is believed to inhibit proliferation. ${ }^{20}$ Due to the positive effects of metformin to the signals inside the cells, including NF-kB signals and $\mathrm{PI} 3 \mathrm{~K} / \mathrm{AKT} / \mathrm{mTOR}$ signals, metformin may lower the expression of local oestradiol, inhibit the inflammatory process, decrease proliferation rates, and simultaneously increase cell apoptosis that will lead to ectopic endometriosis tissue regression and normal regeneration. ${ }^{21,22}$ Yilmaz et al. and Oner G. et al. reported that the administration of metformin in endometriosisinduced mice caused a significant reduction of endometrial implants. ${ }^{23,24}$ In a study shown by Takahashi et al., endometrial cancer cells that were treated with metformin exhibited increased ratio of $\mathrm{Bax} / \mathrm{Bcl}-2 .{ }^{25}$ However, the effect of metformin on $\mathrm{Bcl}-2 / \mathrm{Bax}$ expression ratio and endometrial implants in endometriosis models hasn't been determined in a single research. In this study, the efficacy of metformin for endometriosis therapy will be assessed from Bcl-2/Bax ratio, as well as the size of endometrial implant area in endometriosis mice models.

Table 2. Bax expression in Balb/c mice in all groups

\begin{tabular}{cccc}
\hline Group & Mean \pm SD & Median & $($ Min-Max $)$ \\
\hline P0 & $10.991 \pm 2.1993$ & 12.000 & $(4.6-12.0)$ \\
P1 & $4.682 \pm 3.0337$ & 3.000 & $(2.9-12.0)$ \\
P2 & $6.418 \pm 2.2239$ & 5.900 & $(3.8-10.0)$ \\
\hline
\end{tabular}

\section{MATERIALS AND METHODS}

Ethical Clearance

The ethical clearance was obtained through the Health Research Ethics Commission of the Faculty of Medicine, Universitas Diponegoro and RSUP Dr. Kariadi Semarang with the approval number of 103/EC/H/FK-RSDK/VIII/2018.

\section{Metformin Acquirement}

The Metformin (Metformin 500 mg, Hexpharm Jaya) drug was obtained from a local pharmacy in Surabaya, West Java in a pill form. Every $4 \mathrm{mg}$ of the metformin pill was crushed and dissolved in aquabidest $0.1 \mathrm{ml}$ prior to being given to the mice.

\section{Animal Handling and Research Design}

This study used $33 \mathrm{BALB} / \mathrm{c}$ female mice with body weight ranging from 20 to 30 gram (3 months age). Animals were housed in rat standard polypropylene cages, kept under controlled temperature $\left(25 \pm 2^{\circ} \mathrm{C}\right)$, humidity (40-60\%), and 12 hours of light and 12 hours of dark period. The mice were randomly divided into three different groups, each comprising 11 mice. Each group of mice was placed in a same cage. The first group (P0) represented the control group. The second group (P1) was 
given aquabidest as placebo. The last group (P2) received metformin. All 33 mice were healthy and successfully observed until the end of the study. The experiment was held in the laboratory of the Faculty of Veterinary Medicine Airlangga University. The mice were also obtained from the same laboratory.

To induce immunodeficiency in the mice, the mice from all groups were injected intramuscularly with cyclosporine-A (Sandimmun, Novartis Indonesia) 10 $\mathrm{mg} / \mathrm{kg}$ body weight/day on the first day. ${ }^{26,27}$ Then the mice were given $0.1 \mathrm{ml}$ of injection containing endometriosis tissues using $1 \mathrm{ml}$ disposable syringe with a 16G-sized needle intraperitoneally. The endometriosis tissues were sourced from an endometriosis patient through a surgery in Central General Hospital Dr. Kariadi Semarang. Prior to be injected to the mice, the endometriosis tissues were initially prepared by being centrifuged two times at $2500 \mathrm{rpm}$ with phosphatebuffered saline (PBS), removed from the supernatant, and added with penicillin $200 \mathrm{IU} / \mathrm{ml}$ and streptomycin $200 \mu \mathrm{g} / \mathrm{ml}$. Injection of $17 \beta$-oestradiol (Ethinyl Estradiol) $0.1 \mathrm{ml}$ containing $66 \mathrm{IU}$ of oestradiol was carried out intramuscularly in the mice' thighs on the first and fifth days after the injection of endometriosis tissues. On the 15th day, all mice in the P0 group were terminated to prove the occurrence of endometriosis in mice. The mice were first given ketamine $(40 \mathrm{mg} / \mathrm{kg}$ mouse body weight) and acepromazine $(0.75 \mathrm{mg} / \mathrm{kg}$ mouse body weight) as the anaesthetics prior to be sacrificed. Then, all endometrial implants in the peritoneal cavity of the mice in the $\mathrm{P} 0$ group were taken for examination of the area of tissue endometrial implants, as well as immunohistochemistry and histopathology staining. After completing the evaluation, the mice were then buried. This experiment was performed by a veterinarian.

On the 15th day, the P1 group was given aquabidest as the placebo through a food tube every day for 14 days, which is equivalent to three oestrus cycles. The P2 group received metformin supplementation (4 mg/mouse) via a food tube every day for 14 days. After receiving the intervention for 14 days, then the examination material was acquired on the 29th day of the intervention period.

\section{Histological Preparation}

The cavum abdomen and pelvis peritoneal tissues of the mice were fixed in a $10 \%$ buffer formalin solution for 24 hours. After going through the process of dehydration, clearing, infiltration, and embedding, the immunohistochemistry painting procedures were carried out. The preparations were carried out with endogenous peroxidase block with $0.55 \%$ hydrogen peroxide in methanol for 20 minutes, then put in the microwave for 10 minutes in $10 \mathrm{mM}$ citrate buffer, $\mathrm{pH} 6.0 .^{28}$ The preparation was then placed in PBS, $\mathrm{pH} 7.4$ for five minutes that was added with $3 \%$ normal horse serum (NHS) blocking serum for 20 minutes. The primary antibodies and secondary antibodies were added after removal the excessive NHS. Subsequently, the preparation was washed with PBS, $\mathrm{pH} 7.4$ for two minutes. After that, the peroxidase-conjugated streptavidin (Pierce, USA) 1/1500 was diluted with NHS for 60 minutes. The second washing was done in PBS $\mathrm{pH} 7.4$ for two minutes. Then peroxidase solution was added $25 \mathrm{mg}$ Diaminobenzidine Tetrahydrochloride (Sigma. Cat. No. D5637) in Tris $\mathrm{HCl}$ buffer and $50 \mu \mathrm{g}$ $30 \% \mathrm{H} 2 \mathrm{O} 2$ for 15 to 20 minutes. The staining with Methyl Green was done after the preparation was washed again in PBS pH 7.4 for two minutes. After the preparation dried, the specimen was ready for the Bcl-2 and Bax expression examination.

\section{Bcl-2 and Bax Expression and Endometrial Implant Area Examination}

The Bcl-2 and Bax expression value was obtained by immunohistochemistry staining method and measured by the Rammele Score Index (Immuno Reactive Score/IRS). ${ }^{28}$ The presence of Bcl-2 and Bax expression was identified with brown-coloured chromogen in the immunohistochemistry staining. The ratio of $\mathrm{Bcl}-2 / \mathrm{Bax}$ expression was acquired by dividing the $\mathrm{Bcl}-2$ expression value by the Bax expression value. The measurement of the endometrial implant area was done by performing scissor incisions to extract the endometrial implants of the mice. The image of endometrial implant area was made on a millimetre block paper, then the crosssectional area of endometrial implant was measured in millimetre unit using the computer tracing method with the software 'Image Raster'. ${ }^{26}$ This was performed by an anatomic pathologist expert.

\section{Data Analysis}

The data normality test held for the $\mathrm{Bcl}-2 / \mathrm{Bax}$ expression ratio and endometrial implants was completed using the Shapiro-Wilk test. The data distribution of Bcl2/Bax ratio expression and the extent of endometrial implant variables were stated as normal due to the value ( $>$ > 0.05). The mean difference test of all groups was analysed using the one-way ANOVA test, whereas the mean difference test between groups was completed using the unpaired t-test (LSD/Least Significance Difference). The differences would be considered significant by a $\mathrm{p}<0.05$.

\section{RESULTS \\ Placebo and Metformin Effect on Bcl-2/Bax Expression Ratio}

The expression of Bcl-2 and Bax of the mice models from each study group can be seen in Figure 1. The highest mean Bcl-2 expression value was found in P0 $(8,973 \pm 2.1809)$, followed by P1 $(3.764 \pm 2.4188)$ and P2 $(2.773 \pm 0.5081)$. On the other hand, the group with the highest mean Bax expression was P0 (10.991 2 2.1993), followed by P2 $(6.418 \pm 2.239)$ and P1 (4.682 \pm 3.0337$)$. Based on the Bcl-2/Bax expression ratio of the endometriosis mice models, the lowest ratio was found in P2 $(0.4645 \pm 0.121)$, followed by P1 $(0.8000 \pm 0.108)$ and P0 (0.8391 \pm 0.196$)$. Determination of the mean differences between groups using the T-test (LSD) revealed that the mean expression ratio of $\mathrm{Bcl}-2 / \mathrm{Bax}$ in group P1 was not significantly different relative to the mean expression ratio of $\mathrm{Bcl}-2 / \mathrm{Bax}$ in group $\mathrm{P} 0(\mathrm{p}=$ 0.537). However, the mean expression ratio of $\mathrm{Bcl}-2 / \mathrm{Bax}$ in the P2 group was significantly lower from the mean expression ratio of $\mathrm{Bcl}-2 / \mathrm{Bax}$ in the $\mathrm{P} 0$ group $(\mathrm{p}<0.001)$ and also significantly lower from the average expression ratio of $\mathrm{Bcl}-2 / \mathrm{Bax}$ in the $\mathrm{P} 1$ group $(\mathrm{p}<0.001)$ (Table 3$)$. 

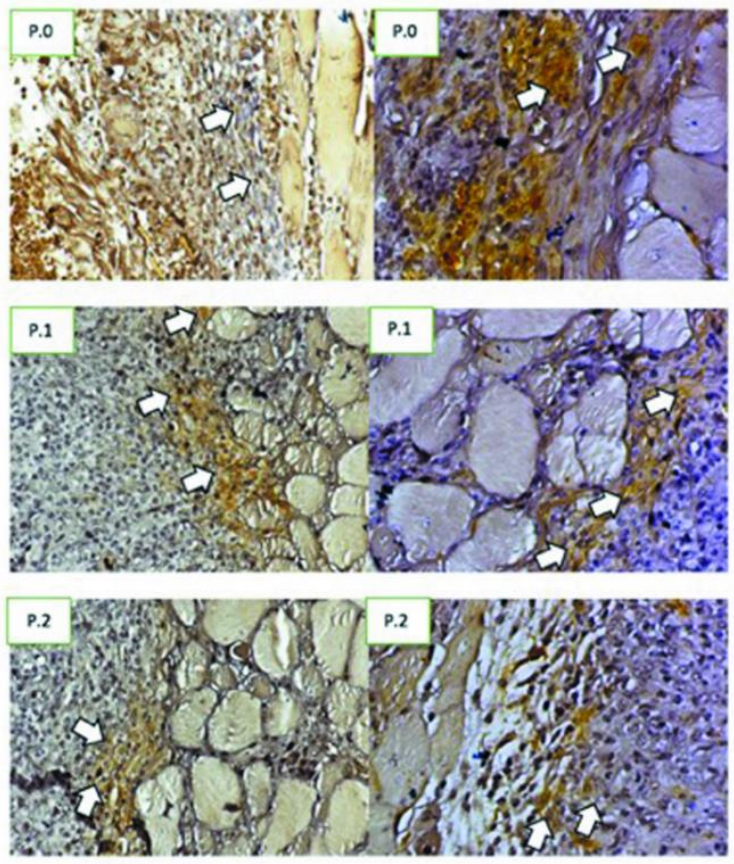

Figure 1. Immunohistochemistry staining of Bcl-2 Expression (left, P0, P1, dan P2) and Bax Expression (right, $\mathrm{P} 0, \mathrm{P} 1$, and $\mathrm{P} 2$ ). The arrow marks show the Bcl-2 and Bax expression on the mice endometrial tissue, characterised by the brown-coloured chromogen, respectively.

Table 3. Mean difference test of Bcl-2/Bax expression ratio in all groups

\begin{tabular}{cccc}
\hline Group & $\mathbf{N}$ & Mean \pm SD & P value* \\
\hline $\mathrm{P} 0$ & 11 & $0.8391 \pm 0.196$ & $<0.001$ \\
$\mathrm{P} 1$ & 11 & $0.8000 \pm 0.108$ & \\
$\mathrm{P} 2$ & 11 & $0.4645 \pm 0.121$ & \\
\hline *One-way Anova test \\
*The result of comparison between groups with \\
LSD test. \\
$\mathrm{P} 0$ vs $\mathrm{P} 1: \mathrm{p}=0.537 ; \mathrm{P} 0$ vs $\mathrm{P} 2: \mathrm{p}=0.001 ; \mathrm{P} 1$ vs $\mathrm{P} 2:$ \\
$\mathrm{p}=0.001$
\end{tabular}

\section{Mean Area of Endometrial Implants}

The highest mean endometrial implant area of endometriosis-induced mice was found in P0 $(137.9355 \pm 50.82254 \mathrm{~mm})$, followed by P1 $(112.4445 \pm 48.1336 \mathrm{~mm})$ and $\mathrm{P} 2(23.3527 \pm 22.27861$ $\mathrm{mm})$. The subsequent analysis to determine the mean difference between the implant area between groups using the t-test (LSD) showed that the mean area of endometrial implants in the P1 group did not have any significant difference from the mean area of endometrial implants in the P0 group ( $\mathrm{p}=0.169)$. The mean area of endometrial implants in the P2 group was significantly lower relative to the mean area of endometrial implants in the P0 group $(p<0.001)$ and also statistically lower compared to the mean area of endometrial implants in the P1 group ( $<<0.001)$ (Table 4$)$.

\section{DISCUSSION}

Endometriosis is a condition where ectopic endometrial cells show abnormal proliferation and apoptosis rate. Apoptosis has a major function in the maintenance of tissue homeostasis and the elimination of excessive or dysfunctional cells. A study reported that normal endometrial cells of healthy women that are removed during menstruation will not continue to live outside of the ectopic location due to the programmed cell death. ${ }^{29}$ Meanwhile, a lowered apoptosis rate may enhance the ectopic survival and implantation of these cells, which eventually boost endometriosis abnormal growth. The increased expression levels of anti-apoptotic factors and decreased pro-apoptotic factors have been linked to the incapability of endometrial cells to send out distressed signals and/or the capability to evade from death. $^{29}$

Table 4. Mean difference test of endometrial implant area in all groups

\begin{tabular}{llll}
\hline Group & $\mathbf{N}$ & Mean \pm SD & P value* $^{*}$ \\
\hline $\mathrm{P} 0$ & 11 & $137.9355 \pm 50.82254$ & $<0.001$ \\
$\mathrm{P} 1$ & 11 & $112.4445 \pm 48.1336$ & \\
$\mathrm{P} 2$ & 11 & $23.3527 \pm 22.27861$ & \\
\hline *One-way Anova test & \\
*The result of comparison between groups with \\
LSD test. \\
$\mathrm{P} 0$ vs $\mathrm{P} 1: \mathrm{p}=0.169 ; \mathrm{P} 0$ vs $\mathrm{P} 2: \mathrm{p}=<0.001 ; \mathrm{P} 1$ vs $\mathrm{P} 2:$ \\
$\mathrm{p}=0.001$
\end{tabular}

The balance of Bcl-2/Bax expression has a vital role in the process of cell death, in which a low value of the ratio will induce apoptosis. The application of the Bcl2/Bax expression ratio is more useful for apoptosis determination compared to the expression of $\mathrm{Bcl}-2$ or Bax individually due to the strong association between the high apoptotic activity and the low level of Bcl-2/Bax expression ratio. ${ }^{6}$ Based on the results of the present study, the administration of metformin in endometriosis mice (P2) reduced the balance of Bcl-2/Bax expression twice higher compared to the group that was given aquabidest (P1) and the control group mice (P0). It can be assumed that the administration of metformin can increase apoptosis in endometriosis mice, characterised with the lower $\mathrm{Bcl}-2 / \mathrm{Bax}$ expression ratio.

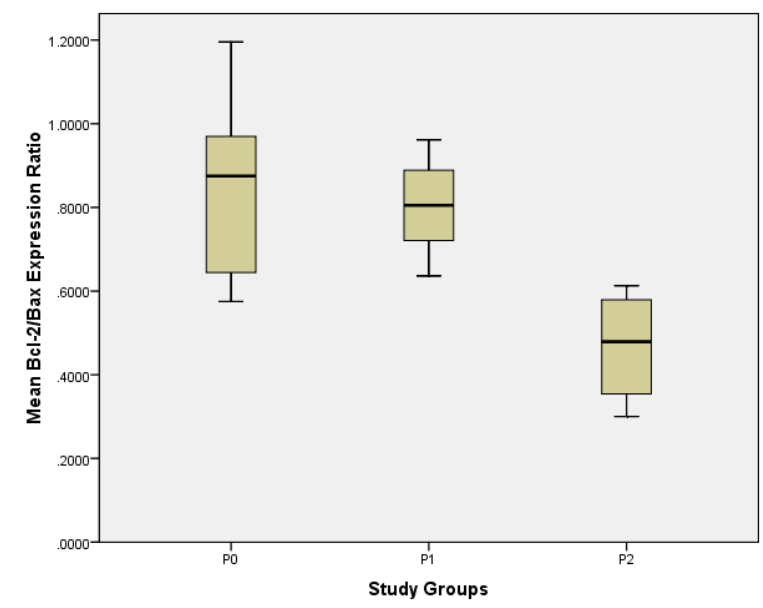

Figure 2. Comparison of $\mathrm{Bcl}-2 / \mathrm{Bax}$ expression ratio of Balb/c endometriosis mice model

The findings of the present research are consistent with the previous research conducted by Oner et al. and Tian et al. in mice with endometriosis models, in which the administration of metformin showed an improvement 
of endometriosis and even a reduction in the size of endometrial implants. ${ }^{24,30}$ Metformin can induce the death of the cells in eutopic endometrium by reducing the expression of $\mathrm{Bcl}-2$ protein and increasing expression of $\mathrm{p} 53$ and Bax. ${ }^{22}$ The effect of metformin on the endometrial implants is assumed to be caused by the action of metformin on AMPK and inhibits prostaglandin and inflammatory reactions. Metformin can lower the activity of aromatase enzyme and improve the hyperandrogenic environment by increasing the content of sex hormone-binding globulin (SHBG), thus the content of oestradiol in the circulation and endometrium is lowered. ${ }^{24}$

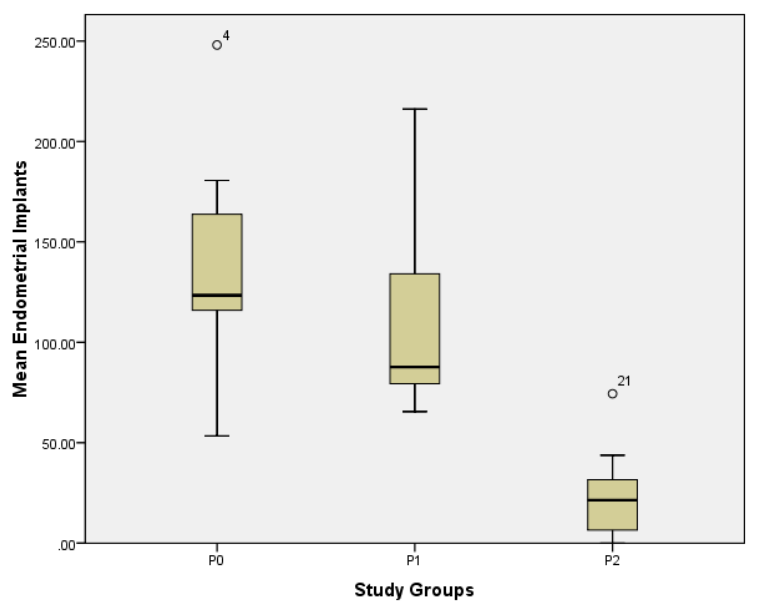

Figure 3. Comparison of endometrial implant area of Balb/c endometriosis mice model

Metformin decreases the stimulated StAR expression by PGE2 by preventing the translocation of cAMP response binding element protein (CREB)-regulated transcription coactivator 2 (CRTC2) which is generally induced by PGE2. Metformin performs this action by increasing AMPK phosphorylation, thus, the CREBCRTC2 complex will not be formed. StAR plays a major role in the process of steroidogenesis by providing continuous cholesterol supply for oestradiol production. StAR stimulates cholesterol entry into mitochondria where cholesterol is converted to pregnenolone, then to androstenedione, oestrone, and finally to oestradiol. As a result of the administration of metformin, the capacity of stromal cells that convert androstenedione to oestrone, which depends on aromatase activity, is decreased. DNA synthesis, as a marker of proliferation, also decreases. It is believed that metformin may regulate and activate AMPK, which then inhibits the mTOR pathway through TSC2 protein. ${ }^{31-33}$

The limitations of this research were to assess data (Bcl-2/Bax expression ratio and endometrial implants) before the intervention was carried out in the control group (P0), where the value was considered the same for the pre-intervention data in the $\mathrm{P} 1$ group and $\mathrm{P} 2$ group. This has happened because to obtain pre-intervention data, the mice must be terminated and their peritoneum must be taken to measure the endometrial implants and sample preparation for the immunohistochemical examination to assess $\mathrm{Bcl}-2 / \mathrm{Bax}$ expression ratio. Additionally, the mice' insulin resistance status was also not tested.

\section{CONCLUSION}

This study demonstrated that metformin administration on mice with endometriosis, positively improved the $\mathrm{Bcl}-2 / \mathrm{Bax}$ expression ratio which suggests a higher rate of apoptosis compared to the group that was given placebo. Furthermore, the mice group that was given metformin also reported a reduction in the size of the endometrial implants, possibly through the metformin activity on the AMPK, hence, inhibiting prostaglandin, inflammatory reactions, and mTOR pathway. In conclusion, the result of the present study shows the potential of metformin to be developed as the treatment for endometriosis patients and may prompt future research on this particular field.

\section{ACKNOWLEDGEMENT}

All authors would like to thank every staff of Reproductive Endocrinology and Fertility Division of Diponegoro University and Department of Veterinary Embryology of Airlangga University.

\section{REFERENCES}

1. Giudice LC. Clinical practice. Endometriosis. N Engl J Med. 2010;362(25):2389-98.

2. Pabona JMP, Simmen FA, Nikiforov MA, Zhuang D, Shankar K, Velarde MC, et al. Krüppel-like factor 9 and progesterone receptor coregulation of decidualizing endometrial stromal cells: implications for the pathogenesis of endometriosis. $\mathbf{J}$ Clin Endocrinol Metab. 2012;97(3):E376-92.

3. Harada T, Kaponis A, Iwabe T, Taniguchi F, Makrydimas G, Sofikitis N, et al. Apoptosis in human endometrium and endometriosis. Hum Reprod Update. 2004;10(1):29-38.

4. Stratton P, Berkley KJ. Chronic pelvic pain and endometriosis: translational evidence of the relationship and implications. Hum Reprod Update. 2011;17(3):327-46.

5. Reed JC. Mechanism of Apoptosis. Am J Pathol. 2000;157(5):1415-30.

6. Poeta G Del, Venditti A, Principe MI Del, Maurillo L, Buccisano F, Tamburini A, et al. Amount of spontaneous apoptosis detected by $\mathrm{Bax} / \mathrm{Bcl}-2$ ratio predicts outcome in acute myeloid leukemia (AML). Blood. 2003;101(6):125-31.

7. Omer NA, Taher MA, Aljebory HDS. Effect of Metformin Treatment on some Blood Biomarkers inWomen with Endometriosis. Iraqi J Pharm Sci. 2016;25(1):28-36.

8. Bedaiwy MA, Barker NM. Evidence based surgical management of endometriosis. Middle East Fertil Soc J. 2012;17(1):57-60.

9. Dunselman GAJ, Vermeulen N, Becker C, CalhazJorge C, D'Hooghe, De Bie B, et al. ESHRE guideline: management of women with endometriosis. Hum Reprod. 2014;29(3):400-12.

10. Elnashar A. Emerging treatment of endometriosis. Middle East Fertil Soc J. 2015;20(2):61-9.

11. Rizk B, Fischer AS, Lotfy HA, Turki R, Zahed HA, Malik R, et al. Recurrence of endometriosis after hysterectomy. Facts, Views Vis ObGyn. 2014;6(4):219-27. 
12. Bozdag G. Recurrence of Endometriosis: Risk Factors, Mechanisms and Biomarkers. Women's Heal. 2016;11(5):693-9.

13. Selçuk I, Bozdağ G. Recurrence of endometriosis; risk factors, mechanisms and biomarkers; review of the literature. J Turkish Ger Gynecol Assoc. 2013;14(2):98-103.

14. Cakmak H, Guzeloglu-Kayisli O, Kayisli UA, Arici A. Immune-endocrine interactions in endometriosis. Front Biosci. 2009;1:429-43.

15. Leyendecker G, Wildt L, Mall G. The pathophysiology of endometriosis and adenomyosis: tissue injury and repair. Arch Gynecol Obstet. 2009;280(4):529-38.

16. Yang L, Ma B, Sun G, Dong C, Ma B. Antiproliferative and antiangiogenic effects of metformin on multidrug-resistant MCF-7 cells. Int J Clin Exp Med. 2018;11(7):6776-83.

17. Gong L, Goswami S, Giaomini KM, Altman RB, Klein TE. Metformin pathways: pharmacokinetics and pharmacodynamics. Pharmacogenet Genomics. 2012;22(11):820-7.

18. Song R. Mechanism of Metformin: A Tale of Two Sites. Diabetes Care. 2016;39:187-9.

19. Foda AA, Aal IAA. Metformin as a new therapy for endometriosis, its effects on both clinical picture and cytokines profile. Middle East Fertil Soc J. 2012;17:262-7.

20. Duque JE, López C, Cruz N, Samudio I. Antitumor mechanisms of metformin: Signaling, metabolism, immunity and beyond. Univ Sci. 2010;15(2):122-9.

21. Gargett CE, Schwab KE, Deane JA. Endometrial stem/progenitor cells: the first 10 years. Hum Reprod Update. 2016;22(2):137-63.

22. Wu J, Xie H, Yao S, Liang Y. Macrophage and nerve interaction in endometriosis. J Neuroinflammation. 2017;14(53):1-11.

23. Yilmaz B, Sucak A, Kilic S, Lortlar N, Sut N, Gungor T. Metformin regresses endometriotic implants in rats by improving implant levels of superoxide dismutase, vascular endothelial growth factor, tissue inhibitor of metalloproteinase-2, and matrix metalloproteinase-9. Res Reprod Endocrinol Infertil. 2009;202(4):368 E1-8.

24. Oner G, Ozcelik B, Ozgun MT, Serin IS, Ozturk F, Basbug M. The effects of metformin and letrozole on endometriosis and comparison of the two treatment agents in a rat model. Hum Reprod. 2010;25(4):932-7.
25. Takahashi A, Kimura F, Yamanaka A, Takebayashi A, Kita N, Takahashi K, et al. Metformin impairs growth of endometrial cancer cells via cell cycle arrest and concomitant autophagy and apoptosis. Cancer Cell Int. 2014;14(53):1-12.

26. Trisetyono Y, Widjiati W, Hidayat ST, Pramono N. Antioxidant Herbs Supplementation Inhibits Endometriosis Extension in Mice. J Biomed Transl Res. 2019;5(2):53-61.

27. Glamour S, Hidayat ST, Prianto AS, Widjiati W. The Differences of Integrin $\alpha v \beta 3$, Leukemia Inhibitory Factors Expression and Superoxide Dismutase Serum Concentration in the Provision of Kebar Extract (Biophytum petersianum Klotczh), Metformin, and Their Combination to Mouse models of Endometriosis. 2018. 2018;4(1):1-8.

28. Hapsari A, Hendarto H, Widjiati. Hylocereus Polyrhizus Peel Ethanol Extract- the Potential Effect to Tumor Necrosis Factor-A, Macrophage, and Matrix Metalloproteinase-9 in Endometriosis Mice. J Int Dent Med Res. 2017;10(3):1070-3.

29. Nasu K, Yuge A, Tsuno A, Nishida M, Narahara M. Involvement of resistance to apoptosis in the pathogenesis of endometriosis. Histol Histopathol. 2009;24:1181-92.

30. Tian C, Chen S, Tong L. Induction of Ectopic Endometrial Apoptosis by Metformin in Endometriosis. J Pract Obstet Gynecol. 2012;6:28.

31. Kinaan M, Ding H, Triggle CR. Metformin: An Old Drug for the Treatment of Diabetes but a New Drug for the Protection of the Endothelium. Med Princ Pract. 2015;24(5):401-15.

32. Xu J-N, Zeng C, Zhou Y, Peng C, Zhou Y-F, Xue Q. Metformin inhibits StAR expression in human endometriotic stromal cells via AMPK-mediated disruption of CREB-CRTC2 complex formation. J Clin Endocrinol Metab. 2014;99(8):2795-803.

33. Petchsila K, Prueksaritanond N, Insin P, Yanaranop M, Chotikawichean N. Effect of Metformin For Decreasing Proliferative Marker in Women with Endometrial Cancer: A Randomized Double-Blind Placebo-Controlled Trial. Asian Pacific J Cancer Prev. 2020;21(3):733-41. 